\title{
"Desenvolvendo-me por inteiro": cidadania, neoliberalismo e saúde contemporânea no currículo de Educação Física
}

Deborah Lupton

\begin{abstract}
Resumo: Recentemente, em vários estados australianos, os campos de educação em saúde e educação física têm sido articulados nas escolas em uma única área de ensino. Este artigo identifica discursos a respeito de saúde que se evidenciam no contexto de um currículo contemporâneo de educação física em saúde, especificamente aquele que está sendo aplicado nas escolas australianas do Estado de Victoria. Por intermédio da análise do currículo e de narrativas de professores a respeito dos princípios curriculares, e de suas experiências em implementá-los, fica demonstrado que atualmente são predominantes noções particulares de saúde relacionadas aos ideais neoliberais de cidadania, hdlismo e identidade pessoal. Há uma forte evidência da influência dos pressupostos da "nova saúde pública" e de idéias a respeito da importância do controle emocional e da auto-estima, tanto no currículo quanto nos relatos dos professores. No entanto, argumenta-se que, ao mesmo tempo em que os ideais dominantes do currículo são geralmente aceitos pelos professores, há também evidências de resistência, intencionais ou não, a estes mesmos ideais no âmbito escolar. Palavras-chave: Educação Física, Educação em Saúde, Currículo e Nova Saúde Pública.
\end{abstract}

\section{Introdução}

Embora haja, tradicionalmente, uma ligação conceitual entre boa saúde e atividade física, centrada na idéia "mente sã, corpo são", foi nos anos 80 e 90 que o foco nessa inter-relação se aprofundou. A abordagem da "nova educação física", que surgiu na Grã-Bretanha, por exemplo, incluía uma ênfase na boa saúde como um resultado da $\begin{array}{llll}\text { educação } & \text { física } & \text { (Evans, } & \text { 1990). }\end{array}$

1 Professora Doutora da School Of Social Sciences And Liberal Studies, Charles Sturt University, Austrália. Pesquisa financiada pelo Austral'ian Research Council, que concedeu auxílio a Derek Colquhoun, Richard Tinning e Deborah Lupton.

Movimento Porto Alegre, v.9, n. 3, p.11-31, set./dez. de 2003 
vários estados australianos, incluindo os dois mais populosos, New South Wales e Victoria, a ligação entre educação em saúde e educação física também tem sido reconhecida. Como resultado, currículos escolares recentemente desenvolvidos têm colocado os dois campos na mesma área. Vários termos são usados em diferentes estados para denotar essa fusão: por exemplo, "desenvolvimento pessoal, saúde e educação física", em New South Wales, e "saúde e educação física", em Victoria.

Análises críticas anteriores chamaram a atenção para os princípios morais e funcionalistas que, explicitamente, estruturavam os currículos de educação física. Algumas críticas aos discursos da educação física relacionada à saúde se baseavam na perspectiva foucaultiana - especialmente aquela interessada no disciplinamento dos corpos individuais - para examinar o modo como aqueles que investiam nesses discursos tentavam converter corpos estudantis em corpos dóceis e, por conseguinte, produtivos. Essas críticas ancoravam-se, predominantemente, nos primeiros escritos de Foucault sobre o funcionamento dos dispositivos arquitetônicos e de vigilância em instituições totais, tais como prisões, asilos e hospitais, utilizados para controlar, regular e disciplinar seus internos. A abordagem explicitamente disciplinar sobre os corpos parece ter sido dominante nos currículos de educação física australianos do final do século XIX e início do século XX, concentrava-se nas rotinas de treinamento, exercícios regulados, inspeção médica dos alunos e jogos coletivos de caráter competitivo. No final do século XIX havia um movimento, delineado pela tradição britânica, que visava especificamente o disciplinamento e a regulação dos corpos, em especial das crianças da classe trabalhadora; e o incentivo às virtudes masculinas positivas de coragem, lealdade e liderança entre os meninos mais privilegiados.

Mas desde então ocorreram importantes modificações na conceituação e no ensino da educação física na Austrália. Por volta dos anos 40, o incentivo à "diversão e ao entusiasmo" e um contínuo interesse dos estudantes pelas atividades físicas e pelo esporte começava a emergir como parte dos objetivos da educação física (Kirk, 1994). Uma ampliação da noção de educação física esteve intimamente ligada ao crescente desenvolvimento, nas crianças, de atributos como flexibilidade, adaptabi-lidade, resolução de problemas e cooperação com outros. Essas qualidades eram vistas como importantes para a classe média 
no desenvolvimento de suas habilidades ocupacionais potenciais (Evans, 1990). Nos anos 50, a "teoria educacional progressiva" americana começou a influenciar, de forma dominante, o currículo de educação física em países como o Reino Unido e a Austrália. Essa abordagem humanista enfatizava o desenvolvimento social e emocional da criança e a noção de cidadania através da educação física, com um foco na "criança por inteiro", em vez do desenvolvimento de habilidades específicas. Esse discurso da "educação pelo movimento" predominou desde então, mas foi contestado por um discurso mais mecanicista da "educação do físico", que privilegia o desenvolvimento de habilidades motoras e a forma física (Wright, 1996).

Conforme argumentei acima, alterações mais recentes possibilitaram que Educação em Saúde e Educação Física fossem delineadas conjuntamente sob uma mesma área de ensino. Ambos os campos foram influenciados pela emergência da "nova saúde pública". Antes a Educação em Saúde ensinada nas escolas tinha uma inclinação mais biomédica e individualista; agora segue uma abordagem preventiva, de inspiração mais social, que caracteriza as políticas de promoção da saúde e a "nova saúde pública". No início dos anos 80 houve a emergência de um movimento que enfatizou, de forma significativa, os aspectos comunitários de promoção da saúde e a noção de escola "promotora de saúde"- No modelo escola "promotora de saúde" as instituições educacionais são posicionadas como "lugares de promoção de saúde", que fornecem "ambientes de apoio" para campanhas de prevenção através do trabalho com as famílias dos estudantes e a comunidade local (Colquhoun; Goltz; Sheehan, 1996; Parsoíis; Stears; Thomas, 1996). Essas mudanças nos princípios curriculares da educação em saúde e da educação física requerem uma abordagem analítica que vai além da noção de relações de poder focadas na disciplina e vigilância rígida dos indivíduos, uma abordagem que por vezes sugere um elemento de coerção. Para os teóricos que se apoiam nos últimos trabalhos de Foucault sobre governamentalidade $(1984 ; 1991)$, as formas pelas quais os imperativos do Estado coincidem com os interesses dos indivíduos e como eles voluntariamente se engajam nos objetivos do governo, como cidadãos responsáveis, são aspectos de grande iíiteresse. Esses teóricos focam suas investigações nos modos pelos quais as técnicas de governo e saber operam em áreas específicas do contexto político neoliberal, e que implica-

Movimento Porto Alegre, v.9, n. 3, p.11-31, set./dez. de 2003 
ções têm na subjetividade e na produção do corpo (Gordon, 1991; Dean, 1997).

O neoliberalismo reitera princípios liberais clássicos, tais como a idéia que cidadãos são atores racionais, autônomos e que o Estado deve evitar a intervenção excessiva nos assuntos privados e no bemestar dos cidadãos. Sob a égide neoliberal, somos encorajados a nos tornar "sujeitos de nós mesmos", a exercermos um tipo de liberdade regulada como parte do funcionamento do poder político. Isso inclui desenvolver atividades de auto-reflexão e auto-aperfeiçoamento, que convergem com os objetivos governamentais, como parte dos nossos esforços para atingir sucesso e felicidade individuais. A noção contemporânea de cidadania define esse movimento como "ativo e individualista em vez de passivo e dependente" (Miller; Rose, 1993, p. 98). A escola age como aparato chave na transferência e reprodução dessas noções neoliberais de cidadania. O cidadão, tal como idealizado em discursos pedagógicos, é um indivíduo capaz de engajar-se em autodisciplina, auto-análise e reflexão éticas. Ao fazêlo, ela ou ele atinge os objetivos projetados pelo Estado para o desenvolvimento e maximização do potencial de sua população.

Esse artigo examina, em um local específico, a construção de vários tipos de subjetividade nos discursos contemporâneos de Educação Física em Saúde. ${ }^{2}$ Lança mão de alguns dos dados coletados em um estudo que investiga discursos contemporâneos concorrentes em currículos escolares de Educação física em Saúde. O estudo reconhece que os modos de implementação dos currículos são resultados de disputas discursivas e de relações de poder provenientes de diversos setores. Sua abordagem teórica incorpora a ênfase foucaultiana na centralidade que os discursos, intimamente conectados com relações de poder, assumem na produção de noções de realidade e relações sociais; apóia-se, também, nos escritos de Bernstein sobre as formas como os discursos funcionam nos contextos da pedagogia e do currículo. Ambas as abordagens enfatizam o flu-

2 Nota de revisão: Educação Física e Educação em Saúde não estão explicitamente articuladas nos documentos curriculares brasileiros como na Austrália. Nos Parâmetros Curriculares Nacionais (PCNs), por exemplo, Educação Física está inserida como uma área de ensino e Saúde como um tema transversal que deve permeartodas as áreas. Por isso, sempre que no texto houver referência àfusão dessas duas áreas no currículo australiano, utilizaremos à expressão 'Educação Física em Saúde' que, apesar de ainda não estar configurada como um campo de estudos no Brasil, permite trabalhar com o sentido proposto pela autora. 
xo das representações discursivas e a disputa que ocorre quando alguns discursos adquirem supremacia sobre os demais em al-guns pontos, enquanto outros são marginalizados. Elas também se preocupam em examinar aspectos de organização e relações sociais dos contextos sócio-culturais e históricos específicos em que os discursos são produzidos, reproduzidos e negociados.

\section{O estudo}

Os principais objetivos do estudo foram os de identificar discursos dominantes inerentes a um currículo específico de Educação Física em Saúde; investigar como esses discursos se formam e são formados por este currículo; bem como identificar e investigar, nos modos pelos quais professores e professoras implementam esses currículos, instâncias de produção, reprodução e negociação (ou resistência) em relação a esses discursos. Concentrando-se no currículo do Departamento de Estudos de Victoria, especificamente nas "áreas fundamentais do ensino" da Educação Física em Saúde, o estudo incluiu a análise de diretrizes políticas relevantes e de materiais textuais didáticos normativos individuais, observações nãoestruturadas de aulas de Educação Física em Saúde, assim como entrevistas com o corpo docente e discente em três locais de Victoria. Os locais selecionados foram uma escola primária e outra secundária na cidade rural de Geelong (a segunda maior do estado, depois de Melbourne) e um campus universitário em Melbourne, onde os conteúdos de Educação Física em Saúde eram lecionados como parte da formação de professores em nível de graduação.

A presente discussão recorre a duas principais fontes de informação (ou textos): primeiro, o documento do Departamento de Estudos que delineia o currículo para a "educação física em saúde" nos primeiros onze anos das escolas primária e secundária e, em segundo lugar, entrevistas gravadas com professores primários e secundários incluídos no estudo. Treze professores de escolas primárias e nove de escolas secundárias, incluindo todos aqueles que lecionavam aspectos do currículo de Educação Física em Saúde em suas escolas, e os diretores e vice-diretores de cada escola, foram entrevistados individualmente, em entrevistas semi-estruturadas, entre 1997 e 1998. Pediu-se a eles que falassem sobre porque e como entraram na área, suas experiências no ensino da Educação em Saúde, Edu-

Movimento Porto Alegre, v.9, n. 3, p.11-31, set./dez. de 2003 
cação Física ou ambas, seus conceitos de "bom" aluno e "bom" professor em relação às aulas de Educação Física em Saúde, suas opiniões a respeito do currículo, as instalações disponíveis na escola e suas idéias sobre o que estavam buscando atingir com seu ensino.

Os documentos curriculares e as transcrições das entrevistas dos professores foram analisadas de acordo com os amplos princípios da análise foucaultiana do discurso. Esses textos foram analisados visando a levantamento de palavras-chave, frases e idéias, bem como a significação de tais palavras, frases e idéias em discursos mais amplos. No contexto da presente discussão os materiais foram lidos com a seguinte questão em mente: Como os textos representam os objetivos e preocupações do currículo de Educação Física em Saúde? Que princípios dominantes eles defendem? Como eles representam alunos e professores? Que noção de saúde é privilegiada nos textos? Quais são seus discursos mais amplos e evidentes (aqueles "fora" dos textos) que estruturam essas representações?

O debate começa com uma análise dos discursos dominantes do currículo do Departamento de Estudos e passa a examinar como os próprios professores articulavam os princípios do currículo e que significados atribuíam aos conteúdos e os objetivos desenvolvidos na Educação Física em Saúde. Discute-se que noções de ética, autogoverno e cidadania são particularmente importantes para os discursos sobre Educação Física e Saúde, tanto no documento curricular quanto na fala dos pro-fessores, e como esses mesmos discursos, centrados sobre um conjunto específico de idéias e princípios neoliberais, repercutem e têm ressonância.

\section{O currículo do Departamento de Estudos}

O documento Curriculum Standards Framework (Estrutura Curricular e Normativa - ECN) do Departamento de Estudos de Victoria é claro sobre a importância de "assuntos distintos, mas relacionados" como elemento fundamental no ensino da Educação Física em Saúde. O documento, publicado em 1995, esboça princípios para o ensino de Educação Física em Saúde nos primeiros onze anos de aprendizado. Há sete linhas que atravessam todo o currículo: movimento humano; atividade física e comunidade; desenvolvimento humano; relações humanas; segu- 
rança; saúde de indivíduos e populações; população e alimento. O ECN observa que:

Estudos na área de Educação Física em Saúde promovem a compreensão da atividade fisica e movimento, alimentação e nutrição, saúde, segurança, desenvolvimento humano e relações humanas. Nesse contexto a área analisa a ação pessoal: crenças, atitudes e valores mantidos pelas famílias, grupos culturais e a comunidade em geral; politicas públicas que afetam a saúde e a atividade fisica; os locais e contextos de atividades na área (Board of Studies, 1995, p. 9).

A fusão das áreas específicas de Educação em saúde e Educação Física na grande área de abrangência do currículo vai se tornando, deste modo, explícita desde o início. O conceito de "saúde" não está apenas concentrado no corpo, mas também na identidade individual, ambientes físicos e culturais; relações políticas e sociais. Entretanto, permanece no ECN um forte enfoque no desenvolvimento de habilidades físicas, ou como o documento coloca, "os princípios biomecânicos e fisiológicos do movimento, que são a base dos padrões de movimentos altamente coordenados,,necessários para o desempenho eficaz" (Board of Studies, 1995, p. 9).

Conforme discutido acima, sob a abordagem predominantemente neoliberal do atual governo democrático na Austrália, como também de outros países de língua inglesa, cidadania presume participação, responsabilidade pelo seu próprio futuro, e adesão voluntária em vez da sujeição coercitiva de cidadãos aos imperativos do governo. Alguns críticos se referem a um "novo prudencialismo"3 ou uma "responsabilização" dos cidadãos que aparece nos discursos neoliberais, nos quais o papel do estado em prover o bem-estar social declina em favor de uma maior ênfase na responsabilidade dos próprios cidadãos por sua saúde e bem-estar (Dean, 1997). Fica claro que essas idéias a respeito de cidadania sustentam o ECN. Ao longo deste documento o foco principal é a "responsabilidade", tanto de indivíduos quanto de comunidades, em agir e interagir com outros de forma pacífica como parte de uma abordagem democrática e participativa de questões relacionadas à saúde. Ao mesmo tempo em que cidadãos têm seus direitos individuais assegurados,

3 Nota de revisão: Este termo está relacionado a um conceito de 'previdência' muito mais individual do que social, uma espécie de "auto-prevenção", na qual o sujeito é responsável pela sua saúde futura e pelo seu próprio destino. Fomentar o desenvolvimento de atitudes e comportamentos mais prudentes diante da vida, incentivar aformação de sujeitos mais precavidos estaria no centro das políticas 
também se espera que cumpram seus deveres como membros da comunidade. O ECN também presume que os estados de saúde são gerenciáveis pelo próprio indivíduo, e que é sua responsabilidade alcançar, proteger e preservar a boa saúde e evitar a doença. Isso contribui para o mais amplo objetivo da promoção de saúde contemporânea, que busca enfatizar a responsabilidade pessoal pelos estados de saúde e representar o sujeito "racional" como aquele que valoriza a boa saúde acima de tudo (Lupton, 1995; Petersen; Lupton, 1996).

Conforme se pôde observar acima, um dos sete fios condutores do currículo busca abertamente articular "Educação Física" e "comunidade" em uma mesma área de ensino. E dada atenção explícita no documento para a importância em "assumir responsabilidades", "resolver conflitos", engajar indivíduos e comunidade na criação e manutenção de ambientes que conduzam à saúde", e para a tensão entre necessidade de "estender as fronteiras das conquistas e conhecimento humanos" e "promover a atenção à saúde e à segurança, minimizando a violência e prevenindo o abuso de substâncias lícitas e ilícitas" (Board of Studies, 1995, p.10 e p.11). Junto a frases-chave arquetípicas que se referem aos resultados desejados na educação - "fomentar a compreensão", "desenvolver conhecimento e habilidades", "explicar", "apreciar", "identificar", "avaliar", "analisar" - a importância da "participação", de "tomar partido ativamente" e de "se desenvolver" também é enfatizada no documento.

De acordo com a noção de "cidadão responsável", privilegiada pelo documento, está a do "eu comunicativo e reflexivo". ${ }^{4} \mathrm{~A}$ necessidade de desenvolver nas crianças a habilidade de identificar, refletir sobre determinada situação, expressar e comunicar seus sentimentos é tratada ao longo de todo o documento. As "relações afetivas" também são consideradas como um "campo de aprendizagem" no ECN, definida como "exploração de contextos sociais e culturais que formam a comunicação e a dinâmica das relações" incluindo dar e receber apoio, assumir responsabilidades e resolver conflitos (Board of Studies, 1995, p.10). Um outro "campo de aprendizagem" é a "identidade",

4 Nota de revisão: Adotamos aqui a justificativa utilizada porTomazTadeu da Silva natradução do texto "Inventando nossos próprios eus", de Nikolas Rose: "Traduzi self por 'eu' consciente da imprecisão dessa tradução, uma vez que 'eu' não tem a mesma conotação de 'reflexividade' de self" (SILVA, Tomas Tadeu da. Nunca fomos humanos: nos rastros do sujeito. Belo Horizonte: Autêntica, 2001). 
que "lida com o papel das perspectivas sociais, culturais e nacionais na produção da imagem que os indivíduos fazem de si mesmos e de como se sentem a respeito de assuntos específicos" (Board of Studies, 1995, p.10).

Em uma noção mais ampla de Educação Física em Saúde não é suficiente, por exemplo, que uma criança de cinco ou seis anos de idade, após seu primeiro ano escolar, "execute atividades motoras simples para que seja considerada capaz de apresentar ações corporais complexas". Espera-se, também, que a criança tenha aprendido a "expressar, através de palavras ou gestos, os sentimentos experimentados durante e imediatamente após a atividade física": por exemplo, "descrevendo as atividades físicas nas quais se sentiu... entusiasmada, amedrontada, relaxada, exausta, vibrante, infeliz, com calor, com frio" (Board of Studies, 1995, p. 19). Quando o aluno chega a 15 ou 16 anos, e atinge os mais altos níveis de aprendizagem nas áreas fundamentais de ensino, dela ou dele se espera capacidade de discutir e entender as posições e sentimentos sociais a respeito de questões controversas como morte e eutanásia, HIV/AIDS, sexualidade e interrupção de gravidez.

O 'eu' ideal representado nesse documento é o do indivíduo capaz de ter consciência de seus próprios sentimentos e comportamentos e o impacto que ambos possam ter sobre os demais. Desde o primeiro ano de escolarização, as crianças são encorajadas a examinar suas crenças e sentimentos, a articulá-los com os dos outros como parte do desenvolvimento de suas habilidades e do seu aprendizado na Educação Física e Saúde. Esta ênfase reflete um discurso mais amplo das sociedades contemporâneas ocidentais, que privilegia a manifestação "franca" da emoção em certos contextos e, ao mesmo tempo, a importância de "conhecer", "trabalhar" e "administrar" o seu 'eu' emocional. De acordo com esse discurso, ser 'muito fechado' ou tentar negar suas emoções leva tanto à aflição psicológica quanto a doenças psicossomáticas.

A representação de saúde no documento está muito ligada a uma noção psicossomática ou "holística" que interliga emoção, espiritualidade e identidade pessoal com características físicas. De fato, um dos objetivos explicitamente declarados do currículo é "desenvolver [nos alunos] uma compreensão do equilíbrio entre aspectos de saúde física, social, espiritual e mental para o efetivo funcionamento dos indivíduos" (Board of 
Studies, 1995, p. 11). Essa noção de saúde vai além do tripé "exercício = aptidão física = saúde", que até recentemente parecia sustentar os programas de educação física (Kirk; Colquhoun, 1989). Ela também incorpora, claramente, elementos da "nova saúde pública" ao enfatizar o "holismo", responsabilidade individual com a saúde ambiental e a importância do contexto local, social e do ambiente físico como elementos que contribuem para os estados de saúde individuais. Esta noção estende o conceito de saúde para todas as esferas da vida, de tal forma que é difícil estabelecer distinções entre o que é e o que não é relevante para este campo (Petersen; Lupton, 1996).

\section{Narrativas dos professores}

As noções de "bom aluno", presentes nos relatos dos professores, convergem com aquelas expressas nos discursos veiculados pelo ECN. A mesma tipologia de subjetividades - "o cidadão responsável" e "o eu comunicativo e reflexivo" - emergiram e foram representados como resultados positivos do currículo. Os relatos dos professores, no entanto, também foram influenciados pelas dificuldades de implementação dos objetivos curriculares no "dia-a-dia" de uma sala de aula.

Portanto, para muitos dos professores entrevistados a "responsabilidade", por exemplo, incluía não apenas participação ativa na manutenção de sua própria saúde, mas também- a habilidade em controlar e apresentar a si mesmos de acordo com a noção de "bom aluno". "Bons alunos" são respeitosos com seus professores e colegas de classe e demonstram entusiasmo para tarefas e atividades solicitadas pelo professor. Eles estão conscientes e sensíveis aos direitos e necessidades dos outros, e demonstram equilíbrio emocional em aula. Eles também são autoconfiantes e prestativos:

Os alunos devem ser engajados para manter a concentração... Devem estar entusiasmados e motivados, e precisam ser positivos... Um bom aluno deveria ser um aluno feliz em aula... Devem ser agentes ativos e não observadores nas aulas de educação fisica - devem ser bastante autoconfiantes, capazes de sair e fazerem coisas por conta própria, assumirem tarefas e conclui-las. (professor, escola secundária) .

A noção de que "bons alunos" deveriam estar preparados para participar em vez de reclamar ou tentar escapar das atividades predominou nos relatos dos professores: 
"Desenvolvendo-me por inteiro"...

/Bons alunos são] aqueles que querem aprender, que são entusiasmados, aqueles que fazem o que é certo, os que são respeitosos e têm boas maneiras. Mas, basicamente, as crianças que você gosta na Educação Física são aquelas que estão sempre participando, que não se queixam ou choramingam, nem tentam escapar das atividades. Você não espera que eles sejam bons, pelo amor de Deus, apenas que tentem! (professora, escola secundária).

A importância do controle das emoções também emergiu nos comentários dos professores. Foi dito que "bons alunos" deveriam ser capazes de administrar suas emoções de modo a não reagirem mal quando perdem ou não se mostram tão aptos a realizar uma dada atividade, e manter uma atitude positiva frente a isso. Deveriam também cooperar com os integrantes de sua equipe, apoiando ao invés de criticar o desempenho dos colegas:

Ao que me consta, bom espírito esportivo é o mais importante. Você sabe, você é bom no esporte se você ganha; você deve ser um bom vencedor e, se você perde, deve ser um bom perdedor, mas ao menos tentou. E se você está jogando num time, vocês sempre incluem os outros garotos e vocês devem se apoiar mutuamente. Eu acho que isso é, provavelmente, a chave para a prática de esportes coletivos - ser um bom tompanheiro de equipe (professor, escola primária).

Noções de responsabilidade não ficaram restritas à conduta dos estudantes, foram também utilizadas para avaliar a postura docente. Alguns professores também se referiram a necessidade de servirem de "exemplos" para seus alunos, demonstrando nas suas próprias ações e forma física como os alunos deveriam se comportar:

Algumas vezes sinto que, porque trabalho na área de educação fisica e saúde, eu deveria estar excepcionalmente em forma e saudável, e que minha vida deveria estar totalmente em ordem para poder aconselhar os outros e assim por diante (professora, escola secundária).

Você deve ser um exemplo para os alunos... Você não pode pregar contra o fumo e depois as crianças verem voce dirigindo fora da escola com um cigarro pendurado na boca. Eu não posso pregar bons hábitos de saúde como um professor de Educação Física se eu não acredito e não tento conservar algum nivel de saúde e forma fisica adequada para minha idade (professor, escola secundária).

Tais declarações reconhecem, claramente, os significados de educação física e saúde que os professores tentam transmitir nas suas aulas. Valores como "manter-se em atividade" em de vez entregar-se à passividade, "forma física", "boa saúde", "uma vida organizada",- equilíbrio emocional e abstenção de comportamentos nocivos, como o hábito de fumar, são apresentados como objetivos essenciais do currículo de Educação Física em Saúde.

Em meio às crenças dos professores sobre o que no currículo seria realizável, havia referência à aquisição de habilida-

Movimento Porto Alegre, v.9, n. 3, p.11-31, set./dez. de 2003 
des, encorajamento à participação em atividades esportivas e desenvolvimento da aptidão física dos escolares (que de outra forma acabariam não se exercitando adequadamente), desenvolvimento da confiança, equilíbrio e habilidades motoras em crianças menores e, para crianças de todas as idades, a habilidade em cooperar com os demais. Vários professores opinaram que na era da televisão e dos jogos de computador, muitas crianças seriam inerentemente sedentárias. Para o seu próprio bem, argumentavam os docentes, as crianças precisavam ser encorajadas pelos seus professores em direção a uma vida fisicamente mais ativa, ou como coloca uma professora da escola primária: "levantar seus traseiros e sair para tomar um pouco de ar fresco".

Em ambas as escolas raramente um professor era o responsável pelas aulas de Educação Física e ao mesmo tempo pelas de Educação em Saúde. Na maioria dos casos mais de um professor era responsável pelo ensino em apenas uma das áreas, dependendo uns dos outros para complementar o que estivessem fazendo. Em função dessa divisão, não causava espanto a existência de distinções, esboçadas pelos entrevistados, entre objetivos atingidos pela Educação Física, de um lado, e os atingidos pela Educação em Saúde de outro. Por exemplo, uma professora de escola secundária identificou tópicos a serem ensinados em Educação em Saúde, tais como "relacionamentos", "resolução de conflito", "sobre o que acontece nas famílias [dos alunos]", "eles precisam de mais estratégias para lidar com o mundo". Ela via a Educação Física como algo mais "prático"-"você sente como se devesse levá-los pra fora e fazer seus corações baterem e torná-los fisicamente ativos" - É importante "fazê-los se mexer".

Alguns professores tiveram dificuldade de trabalhar de forma articulada no transcorrer das aulas de Educação Física, nas suas escolas, aspectos da Educação em Saúde, mesmo que concordassem que elas deveriam estar relacionadas entre si. Como observa um professor de Educação Física do ensino médio:

Tem que haver alguma ligação entre saúde e educação fisica, a posição assumida pela Educação Física e a saúde em geral. Você pode fazer uma ligação sobre como a saúde das pessoas é afetada pelo ambiente... mas em relação ao que acontece com a saúde dentro da escola e o que eu posso fazer em educação fora da escola, não há ligação.

Apesar dessa consciência das diferenças entre os dois campos, a maioria dos professores achava que Educação em Saúde e 
Educação Física eram e deveriam ser tratadas de maneira complementar num currículo combinado.

Eu acho que saúde e Educação Física se combinam, pois seja o que for que fizermos em saúde, estamos falando em manter nossos corpos saudáveis, e basta você enfatizar a importância de estar apto fisicamente e coordenado para atingir isso, e ter um entendimento dessas diversas habilidades [fisicas] (professor, escola primária).

Vários professores se referiram à máxima "mente sã em um corpo são" ao tentarem descrever a relação entre Educação em Saúde e Educação Física:

Eu acho que eles estão relacionados, pois um corpo saudável significa uma mente saudável... Acho que a relação com a saúde está no fato de que existem princípios para uma vida saudável e higiênica, quer seja a higiene básica ou asseio, ou a dieta, ou manter-se longe das drogas, todos esses fatores de segurança. Tudo isso que ensinamos em saúde é muito relacionado e influenciado pelos princípios de educação em saúde (professor, escola secundária).

Alguns professores usaram a noção de saúde "holística", expressa no próprio ECN. Um professor da escola primária comentou que:

Nós tentamos fazer com que as crianças entendam que a saúde é algo global - há um bem-estar emocional, fisico e social, e todos são igualmente importantes. E também é dessa maneira que vejo quando estou lecionando, que eles estão relacionados desse modo. É que o programa de saúde e relações humanas que aplicamos está todo voltado para o desenvolvimento do "eu por inteiro" e o vejo amarrado dessa forma.

Ao ilustrar seu ponto de vista, esse professor falou sobre o programa de saúde e relações humanas que ele lecionou como parte de um tópico sobre o corpo humano. Ele ressaltou a importância de articular o desenvolvimento individual e sensibilidade frente a relações humanas com conhecimento sobre o corpo e como ele funciona, tudo que envolve participação ativa e promoção de responsabilidade consigo mesmo para uma boa saúde:

Parte disso é educação sexual, mas é mais que isso. É sobre como desenvolver a sua personalidade, sua auto-estima, fazer as escolhas certas na sua vida e viver as conseqüencias dessas escolhas. E então, como parte do tópico sobre corpo humano, as crianças também aprendem a respeito de todos os sistemas do corpo, não apenas do sistema reprodutivo, que é uma parte específica do programa de saúde e relações humanas... De qualquer forma, no fim do segundo semestre, as crianças têm uma boa compreensão sobre como seus corpos funcionam e sobre a sua responsabilidade para com eles e como os entendem, cuidam e fazem com que eles fiquem do jeito que querem. E isso inclui o envolvimento com esportes, boa dieta e esse tipo de coisa - tudo isso faz parte. 
Esse professor se referiu à "auto-estima" como um conceito importante. Essa colocação também foi usada nos relatos de vários outros professores como uma maneira de atuar em Educação em Saúde e Educação Física que deveria ser seguida, particularmente aqueles que deram uma visão mais ampla sobre o que o currículo de Educação Física em Saúde deveria conseguir alcançar. Por exemplo, uma professora de uma escola primária comentou que:

Temos uma visão ampla e sadia a respeito do bem-estar do individuo. Não é apenas a Educação Física como ela é pensada nos esportes, mas saúde e relações humanas. Sentimentos saudáveis sobre ter uma boa auto-estima e coisas desse tipo.

Aqueles professores que falaram a respeito de auto-estima, argumentaram freqüentemente que ela se desenvolvia através do domínio das habilidades físicas, como também através da capacidade de interagir socialmente, era importante não só para a performance do aluno na Educação Física em Saúde, mas também para outras áreas acadêmicas e até mesmo nas relações sociais da vida em geral. Boa auto-estima não só envolvia o cultivo de sentimentos positivos a respeito de si mesmo, mas a habilidade de envolver-se com sucesso nas relações com os outros.

Ainda não acho que as pessoas dêem para a saúde a importância que ela deveria ter. Pois, se as crianças não são saudáveis mentalmente e fisicamente, claro que elas não vão fazer seu trabalho, não vão se sair tão bem. Quero dizer, todos sabemos que se a auto-estima está baixa, você não vai se sair bem em matemática, inglês ou qualquer outra coisa... Seus bons alunos, que têm uma boa-autoestima, serão capazes de se relacionar com empatia com outras pessoas e outras crianças (professor, escola primária).

Alguns professores argumentaram que, para desenvolver uma boa auto-estima e encorajar a participação ativa, o professor deve se preocupar em construir uma situação de aprendizado em que os alunos se sintam confiantes. Um professor da escola primária ressaltou que um aluno confiante, que "realmente tenta", deve saber que:

Se eles cometerem um erro, não vão ser reprimidos ou massacrados... deve-se voltar para aquele ambiente positivo e tranqüilizador. As crianças que mais respondem a esse tipo de ambiente, não precisam ouvir "Oh, deixou a bola cair de novo! O quê você está fazendo? Tente de novo, e com mais vontade", e esse tipo de coisa.

Embora a auto-estima não fosse mencionada diretamente no ECN, o enfoque do documento na consciência e manejo emocional, e na saúde "holística", compartilha preocupações si- 
milares. O conceito de auto-estima se tornou fundamental nos discursos de desenvolvimento pessoal e de política educacional (Cruikshank, 1993; Kahne, 1996). Esse conceito, oriundo da psicologia social norte-americana, presume que "acreditar em si mesmo", "autoconfiança", "uma boa auto-imagem" e "auto-afirmação" são todos traços psicológicos positivos que 'empoderam' os indivíduos e favorecem o sucesso na vida, inclusive na escolarização. Isso é parte da pedagogia centrada na criança, que busca afastar-se do controle explicitamente disciplinar para desenvolver na própria criança a habilidade de autocontrole através dessas estratégias, assim como o encorajamento da auto-estima. Baseado como está nas idéias sobre personalidade e psicologia, este é um conceito altamente individualista, dirigido à promoção da realização pessoal.

Entretanto, como aparece em alguns discursos políticos, o conceito de auto-estima vai além de um objetivo pessoal para uma realização que prepara os indivíduos para participar responsável e efetividade como cidadãos (Cruikshank, 1993). Portanto, ele se ajusta perfeitamente à noção de eu empresarial do neoliberalismo, o eu que constantemente trabalha sobre si mesmo. Ao fazer isso, o conceito de auto-estima também tira a atenção dos contextos sociais, estruturais e políticos em que noções de identidade pessoal são desenvolvidas e pelos quais elas são formadas, e conseqüentemente da intervenção do Estado nesses contextos. Aqui, mais uma vez, esta noção se ajusta ao enfoque neoliberal da responsabilização dos cidadãos dando suporte e melhorando a si mesmos com ajuda mínima do Estado, para tornaremse auto-suficientes. Tal modo de governar confia na habilidade dos cidadãos "de reconhecerem, isolarem e agirem com base na sua própria subjetividade, de serem governantes de si mesmos" (Cruikshank, 1993, p. 331).

A idéia de que a auto-estima deveria ser encorajada em todas as crianças, juntamente com a noção de que todos os alunos, independentemente da sua capacidade, deveriam estar dispostos a participar e "tentar" sem medo de falhar, devendo ser encorajados a fazê-lo pelos seus professores, entra em conflito com a idéia de que a competição e a vitória são parte importante das atividades esportivas. Vários professores reconheceram a tensão evidenciada entre querer fazer com que todos os alunos se sintam bem em relação a seus esforços, e a importância de recompensar a boa performance. Como ressaltou uma professora de escola primária: "eu acho que você precisa da competitividade. 
É um mundo duro lá fora e, infelizmente, quando você se candidata a um emprego ou qualquer coisa na vida, você vai ter alguém que é o primeiro, segundo e alguém que é o terceiro". Outra professora de escola primária disse que tinha "sentimentos ambivalentes" sobre a participação em competições: "quero dizer, eu ganhei no esporte antes, e isso é bom, é bom vencer, não há dúvida a respeito disso. $\mathrm{E}$ eu acho que os vencedores e as pessoas que alcançam êxito devem ser reconhecidos". Ela continuou, ressaltando com maior ambivalência, "mas eu acho, eu realmente penso que o principal para o esporte deveria ser o prazer, e que ele fosse bom para a sua saúde; creio eu". Como isso sugere, novos discursos no campo da Educação Física em Saúde algumas vezes competem com discursos mais antigos e estabelecidos, permanecendo em conflito.

\section{Conclusão}

O novo currículo combinado de Educação em Saúde e Educação Física, introduzido nas escolas de ensino fundamental e médio de Victoria, incorpora tanto idéias mais clássicas a respeito de "uma mente sã em um corpo são", quanto o humanismo centrado na criança, surgido no currículo de Educação Física em décadas mais recentes. Ele também respondeu aos atuais discursos da nova saúde pública, promoção de uma saúde mais holística, que envolve aspectos individuais e sociais. O currículo de Educação Física em Saúde é dirigido à promoção do "eu por inteiro", e isso inclui o uso de discursos a respeito da importância da consciência e controle emocionais, e de atributos tais como a auto-estima. Assim, o currículo é dirigido ao cultivo de um tipo específico de pessoa: o cidadão participativo, autônomo, autocognoscente, que é privilegiado pelo neoliberalismo.

Vemos, tanto no currículo quanto nos relatos docentes a respeito de seus objetivos com o ensino do currículo, a convergência de preocupações a respeito do cultivo ético do indivíduo, incluindo a habilidade dos alunos em entender e relacionar os seus sentimentos com os dos outros e de entender a situação social em que a prática acontece, elementos tradicionalmente associados aos objetivos da educação liberal e que têm sido preservados pelas ciências humanas (Hunter, 1993). Esse currículo Educação Física em Saúde une as ciências humanas e sociais com as ciências do movimento humano. Não se trata apenas das formas externas do corpo - tradicionalmente o lugar do currícu-

Movimento Porto Alegre, v.9, n. 3, p.11-31, set./dez. de 2003 
lo de Educação Física - que recebe atenção, mas as operações internas do eu interior que devem ser acessadas e reveladas. O ECN, portanto, aproxima e tenta unificar dois imperativos distintos e concorrentes da Educação Física em Saúde: aquele que vê o campo como central na aquisição de habilidades físicas e aquele que vai, além disso, enfatizando o seu papel no desenvolvimento de capacidades sociais, emocionais e comunicativas nos alunos.

O currículo representa tais objetivos como não-problemáticos e garantidos. Na prática diária dos professores, entretanto, $\mathrm{o}$ alcançá-los não é uma tarefa tão fácil quanto o documento sugere. A maioria dos professores entrevistados no estudo relatou preocupações e objetivos semelhantes àqueles explicitados no currículo, evidenciando certa tensão entre seus ideais e a prática. Os professores se deparam com alunos sem entusiasmo, aqueles que "reclamam e choramingam" e que não estão dispostos a "tentar". Eles lutam com as diferenças que notam entíe o que a Educação em Saúde define como meta de um lado e o que a Educação Física busca alcançar de outro. Eles lidam com estruturas organizacionais nas suas escolas que os forçam a separar em vez de articular Educação em Saúde e Educação Física. Alguns professores, particularmente aqueles que desfrutaram do sucesso no esporte, acham difícil conciliar discursos sobre participação e auto-estima com aqueles sobre a importância de vencer e demonstrar superioridade em relação aos demais. Outros, ao discutirem o peso do compromisso de se apresentarem diante dos alunos como modelos, reconhecem que há um duro trabalho a ser feito sobre si mesmos para assumir e manter a representação de cidadão ideal que o currículo de Educação Física em Saúde impõe.

Como fica sugerido, mesmo em um contexto em que há uma aceitação geral dos princípios subjacentes a um determinado sistema governamental - nesse caso, um currículo oficial produzido por um departamento de ensino estadual - surgem resistências de todos os lados à implementação desses mesmos princípios, sejam elas deliberadas ou não. Projetos de governo e suas estratégias são inevitavelmente parciais, suscetíveis ao não cumprimento da meta devido à complexidade dos interesses em disputa, à diversidade de discursos e instituições envolvidas que tentam dar-lhes sentido e implementá-los (Malpas; Wickham, 1995). Uma ênfase exagerada na produção do corpo disciplina- 
do e dócil na Educação Física em Saúde, valendo-se das obras iniciais de Foucault, não é capaz de reconhecer o tamanho da resistência e dos fracassos das estratégias disciplinares existentes na escola.

"Desarrollándome integralmente": ciudadanía,
neoliberalismo y salud contemporánea en el curriculo de
Educación Física. Resumen: Recientemente, en varias
provincias australianas, los campos de educación en salud y
eduación física han sido articulados en las escuelas en una
única área de enseñanza. Este artigo identifica discursos al
respecto de salud que se evidencian en el contexto de un
curriculum contemporáneo de educación física en salud,
especificamente aquele que está siendo aplicado en las
escuelas australianas de la pro-vincia de Victoria. Por
intermedio de la análisis del curriculum y de narrativas de
profesores al respecto de los principios curriculares, y de
suas experiencias en implementarlos, queda demostrado que
actualmente son predominantes las nociones particulares de
salud relacionadas a los ideales neoliberales de ciudadanía,
holismo e identidad personal. Hay una fuerte evidencia de la
influencia de los presupuestos de la «nueva salud pública» y
de ideas al respecto de la importancia del control emocional y
de la auto-estima, tanto en el curriculum como en los relatos
de los profesores. No entanto, se argumenta que, al mismo
tiempo en que los ideales dominantes del curriculum son
general-mente aceptados por los profesores, hay también
evidencias de resistencia, intencionales o no, a estes mismos
ideales en el ambito escolar.
Palabras-clave: Educación Física, Educación en Salud,
Curriculum y Nueva Salud Pública.

Movimento Porto Alegre, v.9, n. 3, p.11-31, set./dez. de 2003 
Developing the whole me': citizenship, neo-liberalism and the contemporary health and physical education curriculum

Abstract: In several Australian states in recent years, the fields of health education and physical education have been united in schools as a single learning area. This article identifies the discourses on health that are evident in the context of a specific contemporary health and physical education curriculum - that operating in Australian schools in the state of Victoria. By analysing the curriculum document and teachers' accounts of the principles of the curriculum and their experiences in teaching it, it is shown that particular notions of health, related to neo-liberal ideas about citizenship, holism and personal identity, currently dominate. There is strong evidence of the influence of 'the new public health' tenets and ideas about the importance of emotional management and self-esteem in both the curriculum document and teachers' accounts. It is argued, however, that while the dominant tenets of the curriculum are generally espoused by teachers, there is also evidence of resistance, either intended or unintended, to these tenets at the site of the school. Keywords: Physical Education, Health Education, Curriculum, New Public Health.

\section{Referências}

BOARD OF STUDIES (Victoria). Health and physical education curriculum and standards framework. Melbourne: Board of Studies, 1995.

COLQUHOUN, D.; GOLTZ, K. and SHEEHAN, M. The health promoting school: policies, practices and programs in Australia. Sydney: Harcourt Brace, 1996.

CRUIKSHANK, B. Revolutions within: self-government and self-esteem. Economy and Society, 22(3), 327-44, 1993.

DEAN, M. Sociology after society. In: OWEN, D. (ed.), Sociology after postmodernism. London: Sage, pp. 205-28, 1997.

EVANS, J. Ability, position and privilege in school physical education. In: KIRK, D. and TINNING, R. (eds.), Physical education, curriculum and culture: critical issues in the contemporary crisis. Basingstoke: The Falmer Press, pp. 139-68, 1990.

Movimento Porto Alegre, v.9, n. 3, p.11-31, set./dez. de 2003 
FOUCAULT, M. Madness and civilization: a history of insanity in the age of reason. London: Tavistock, 1967.

FOUCAULT, M. Discipline and punish: the birth of the prison. London: Allen Lane, 1977.

FOUCAULT, M. Governmentality. In: BURCHELL, G.; GORDON, C. and MILLER, R (eds.), The Foucau/t effect: studies in govemmentality. Hempel Hempstead: Harvester Wheatsheaf, pp. 87-104, 1984.

FOUCAULT, M. The birth of the clinic: an archaeology of medical perception. New York: Vintage Books, 1975.

FOUCAULT, M. The politics of health in the eighteenth century. In: RABINOW, R (ed.), The Foucault reader. New York: Pantheon Books, pp. 273-89, 1984.

GORDON, C. Governmental rationality: an introduction. In: BURCHELL, G., GORDON, C. and MILLER, P. (eds.), The Foucault effect: studies in govemmentality. Hemel Hempstead: Harvester Wheatsheaf, pp. 1-52, 1991.

HARGREAVES, J. Sport, power and culture: a social and historical analysis of popular sports in Britain. Cambridge: Polity Press, 1986.

HUNTER, I. Personality as vocation: the political rationality of the humanities. In: GANE, M. and JOHNSON, T (eds.), Foucault's new domains. London: Routledge, pp. 153-92, 1993.

KAHNE, J. The politics of self-esteem. American Educational Research Journal, 33(1), 322, 1996.

KIRK, D. and SPILLER, B. Schooling for docility-utility: drill, gymnastics and the problem of the body in Victorian elementary schools. In: MEREDYTH, D. and TYLER, D. (eds.), Child and citizen: genealogies of schooling and subjectivity. Brisbane: Institute for Cultural Policy Studies, Griffith University, pp. 103-27, 1993.

KIRK, D. and COLQUHOUN, D. Healthism and physical education. British Journal of the Sociology of Education, 10(4), 417-34, 1989.

KIRK, D. Physical education and regimes of the body. Australian and New Zealand Journal of Sociology, 30(2), 165-77, 1994.

LUPTON, D. The emotional self: a sociocultural exploration. London: Sage, 1998.

LUPTON, D. The imperative of health: public health and the regulated body. London: Sage, 1995.

MALPAS, J. and WICKHAM, G. Governance and failure: on the limits of sociology. Australian and New Zealand Journal of Sociology, 31(3), 37-50, 1995.

MILLER, R and ROSE, N. Governing economic life. In: GANE, M. and JOHNSON, T (eds.), Foucault's new domains. London: Routledge, pp. 75-105, 1993.

Movimento Porto Alegre, v.9, n. 3, p.11-31, set./dez. de 2003 
"Desenvolvendo-me por inteiro"...

PARSONS, C; STEARS, D. and THOMAS, C. The health promoting school in Europe: conceptualising and evaluating the change. Health Education Journal, 55, 311-21, 1996.

PETERSEN, A. and LUPTON, D. The new public health: health and self in the age of risk. Sydney/London: Allen \& Unwin/Sage, 1996.

WRIGHT, J. Mapping the discourses of physical education: articulating a female tradition. Journal of Curriculum Studies, 28(3), 331-51, 1996.

Recebido em: 21/09/2003

Aprovado em: 25/09/2003

Deborah Lupton

14 Arnold Street, Killara, 2071

Australia

dlupton@csu.edu.au

Tradução de Márcia Dornelles, Eduardo Stigger e Carolina Paz Garcia

Revisão Técnica de Alex Branco Fraga (ESEF/UFRGS); Dagmar Meyer (FACED/UFRGS) e Denise Gastaldo (University of Toronto).

Esse texto foi publicado originalmente na Criticai Public Health, v. 9, n. 4, dez. 1999 e teve sua autorização para tradução e publicação no Brasil concedida à Revista Movimento da ESEF/UFRGS pela própria autora e pela Taylor \& Francis Journals, detentora dos direitos autorais do presente artigo.

Movimento Porto Alegre, v.9, n. 3, p.11-31, set./dez. de 2003 